\title{
OBSERVATIONS
}

ON THE

\section{VASCULAR APPEARANCE}

IN THE

\section{H U M A N S T O M A C H,}

WHICH IS KREQUENTIY MISTAKEN FOR INFLAMMATION OF THAT ORGAN.

\author{
BỸ JOHN YELLOLY, M.D. \\ PHYSICIAN TO THE LONDON HOSPITAL.
}

\section{Read July 27, 1813.}

IT must have happened to every one accustomed to the examination of morbid bodies, to see appearances of vascular fulness in the villous coat of the stomach. Such appearances have very frequently been referred to inflammation; but they have probably been but little studied, because; in dissections, the stomach is seldom opened, unless the attention be particularly directed to that organ, either from something remarkable in its external appearance, or some particular symptom affecting it, which may have been the subject of obser. 
vation during life. I have several times been present at the examination of bodies, where the vas. cularity of the villous coat of the stomach was so considerable, as even to give rise to suspicions, that this appearance had been produced by the agency of something deleterious. In some remarkable cases, too, which fell under my own immediate inspection (particularly one of apoplexy, and another of hydrothorax, ) the phænomena now mentioned, existed to a very considerable degree, without there having been present, during life, any symptom which could make an affection of the stomach looked for.

I was therefore induced to embrace frequent opportunities of viewing the state of the inner surface of the stomach; and I so often found in it the appearances alluded to, as to incline me to imagine, that the opinion which is commonly entertained, of their being marks of disease, is not well founded. I thought it, however, desirable to make a continued series of examinations as to this point, in subjects taken indiscriminately, and therefore without any reference to the disease of which they might have died; hoping, by this means, to obtain such a portion of evidence, as might warrant some deduction, as to the ordinary appearances of the villous coat of the human stomach, in the dead body. I shall therefore lay before the Society, an account of twenty successive dissec- 
tions, made by me, with a more particular view to the state of the stomach : and shall then give the appearances which that organ presented, in the bodies of five criminals, who forfeited their lives to public justice, and where there might be expected to be as little deviation as possible, from natural and healthy structure, and appearance*. The twenty dissections were principally made in cases which occurred at the London Hospital, under the care of my colleagues, (the physicians and surgeons of that establishment,) or myself; and the appearances were generally noted down by me at the time of inspection. I shall give one of them separately; but as I am aware that a detail of cases, where there is no material diversity in the individual particulars, is very tedious, I shall reduce the others to a tabular form.

It may be proper to remark, that in removing the stomachs, for the purpose of examination, a ligature was made at each extremity, and a portion of the csophagus and duodenum included within it; and in order that no unnecessary pressure should be made on the tender villous coat in the inversion, an incision was made in the anterior part of the stomach, from the extremity of the duodenum, through the pylorus, of sufficient size to admit of its being readily inverted.

* It will be obvious, from the dates, that several of the cases and observations have been added since this paper was conmunicated to the Society. 
John Bate, aged 36, porter, was admitted into the London Hospital on Feb. 23, 1813, with general dropsy; and after the unsuccessful employment of various means for his relief, he gradually sunk, and died on May 11. There had been no affection of the stomach. He was opened on the day of his death.

In both cavities of the thorax, there was a considerable quantity of bloody serum, and some also in the pericardium. The heart was large and firm; and there was a small and slight adhesion of it to the pericardium. Some bloody serum was found in the abdomen; and a strong band attached the lower part of the ilium, to the peritonæum contiguous to it. The spleen was considerably larger than usual; and it adhered extensively and strongly to the diaphragm, and slightly to the colon. Its substance was firm; and the whole of its external surface (that towards the ribs) was covered with a thin layer of white, smooth, cartilage*. The liver was natural in appearance; but the cystic bile was very pale. Nearly the whole of the great end of the stomach, on the posterior part, including a surface of somewhat a round form, and of about five inches by four in dimension, was of a bright crimson colour, which arose from very numerous points, as if of extravasation, very near the internal surface of the villous coat, and a slight regular vascularity.

* A similar affection of the splecn is described in Bailiie's Morbid Anatomy, p. 256. 
Similar points, well defined, and of various sizes, were seen in other parts of the stomach, particularly near the pylorus. The plicæ were numerous, near the pylorus, and towards the left inferior extremity of the greater curvature. 


\begin{tabular}{|c|c|c|c|c|}
\hline 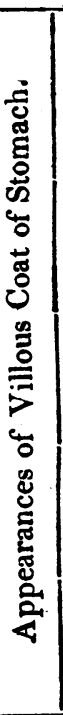 & 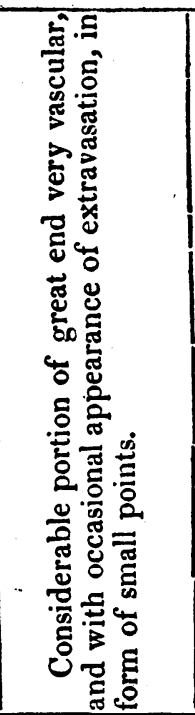 & 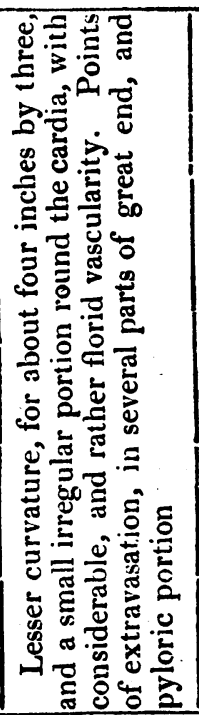 & 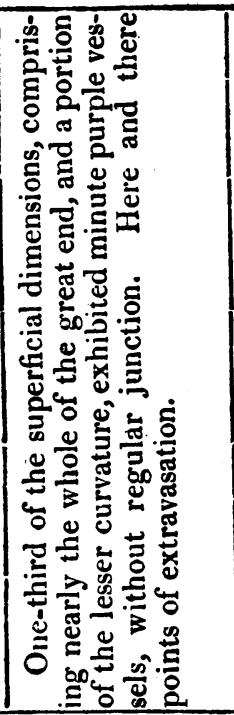 & 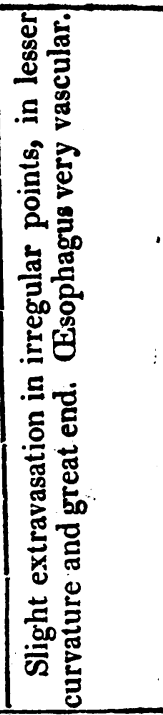 \\
\hline & 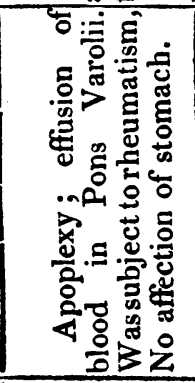 & 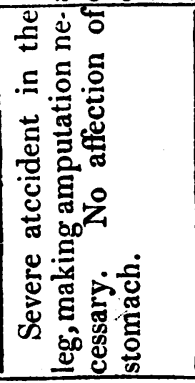 & 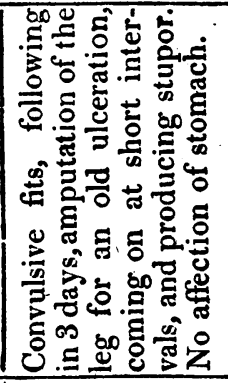 & 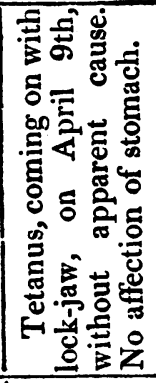 \\
\hline 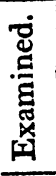 & $\frac{60}{\infty} \frac{-}{\bar{E}}$ & $\dot{0}$ & $\dot{0}$ & 电 \\
\hline 灾 & 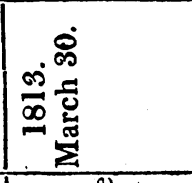 & $\stackrel{\infty}{=}$ & $\dot{ \pm}$ & $\dot{\square}$ \\
\hline $\begin{array}{l}\dot{0} \\
\dot{8} \\
\tilde{\Xi} \\
\text { ż }\end{array}$ & 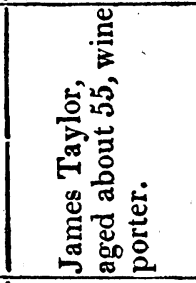 & 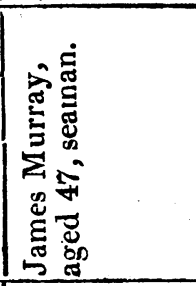 & 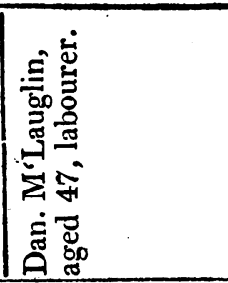 & 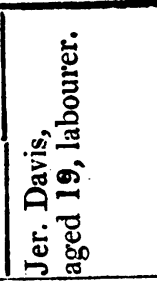 \\
\hline$\dot{\mathrm{O}}$ & 7 & or & $1 \infty$ & $1+$ \\
\hline
\end{tabular}




\begin{tabular}{|c|c|c|c|c|c|}
\hline 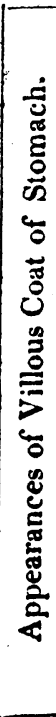 & 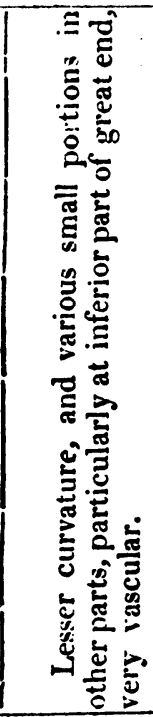 & 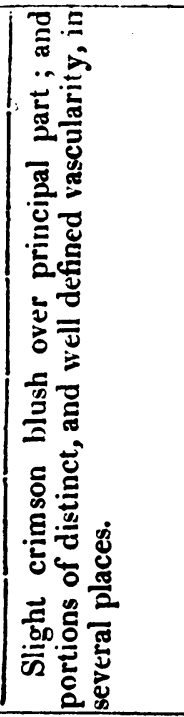 & 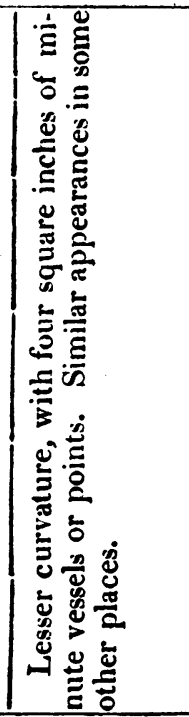 & 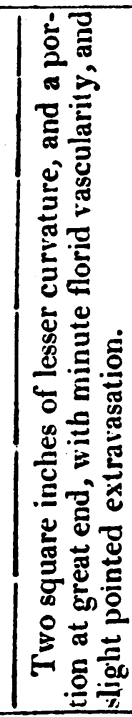 & 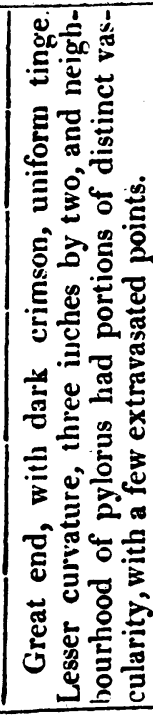 \\
\hline & 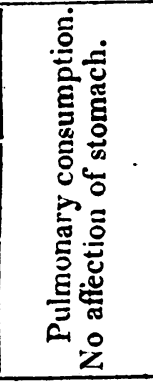 & 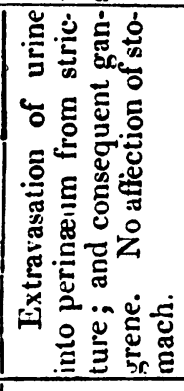 & 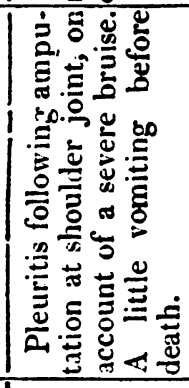 & 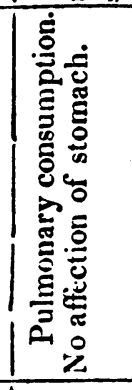 & 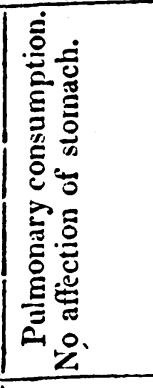 \\
\hline 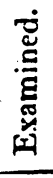 & $\frac{\infty}{\infty} \frac{0}{0}$ & Rे & $\dot{\overrightarrow{0}}$ & $\dot{1}$ & ம் \\
\hline$\stackrel{\stackrel{\mathscr{Q}}{0}}{\mathrm{~A}}$ & $\stackrel{\infty}{\infty} \frac{\dot{\alpha}}{\bar{\vdots}}$ & $\stackrel{\infty}{\mathscr{a}}$ & ஜिं & $\dot{\vec{\theta}}$ & oi \\
\hline 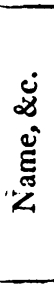 & 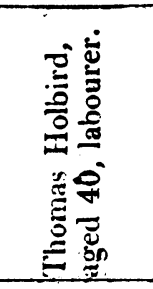 & 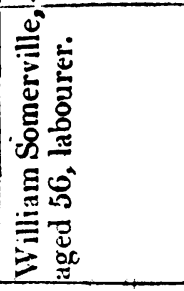 & 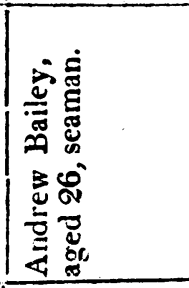 & 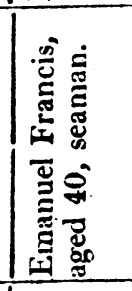 & 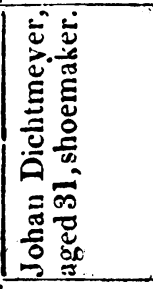 \\
\hline$\dot{\gamma}$ & 20 & 0 & 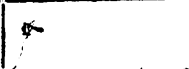 & $\infty$ & o. \\
\hline
\end{tabular}




\begin{tabular}{|c|c|c|c|c|c|c|}
\hline 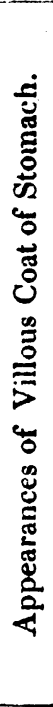 & 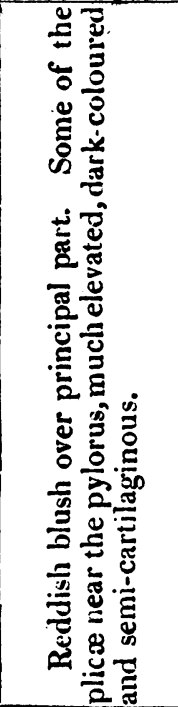 & 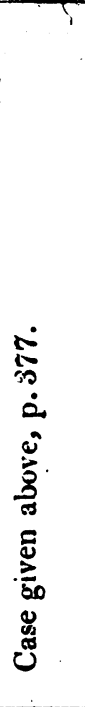 & 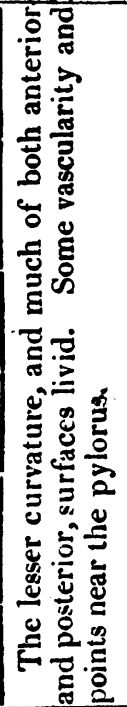 & 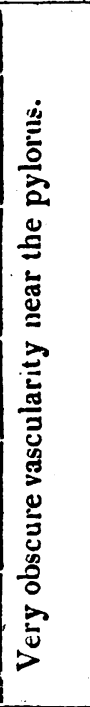 & 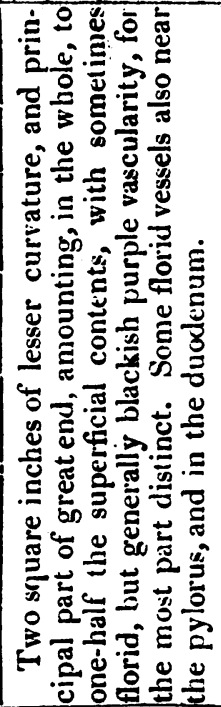 & 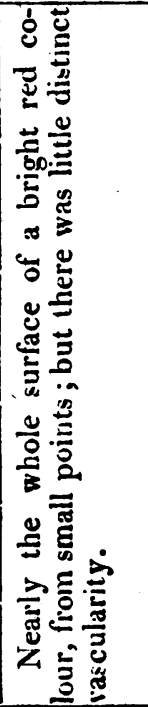 \\
\hline 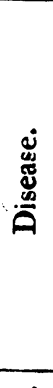 & 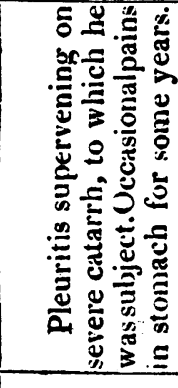 & $\frac{\dot{0}}{\frac{0}{0}}$ & 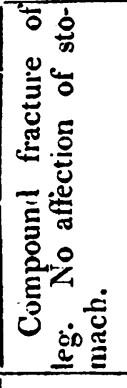 & 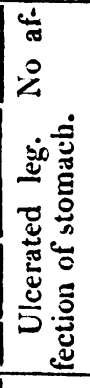 & 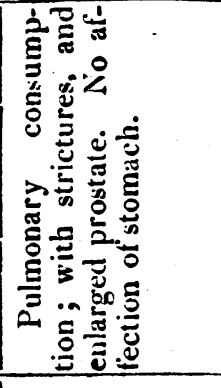 & 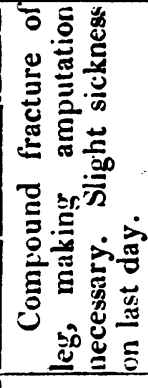 \\
\hline 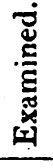 & $\stackrel{\infty}{\infty} \underset{0}{\infty}$ & $\ddot{z}$ & 20 & a) & $\dot{\vec{\sigma}}$ & $\dot{\pi}$ \\
\hline 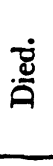 & $\stackrel{\infty}{\infty} \underset{\sum}{\infty}$ & $=$ & $\dot{t}$ & $\stackrel{\theta}{\sim}$ & 今 & $\dot{\sigma}$ \\
\hline 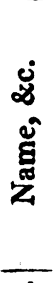 & 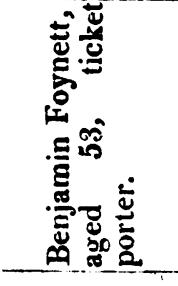 & 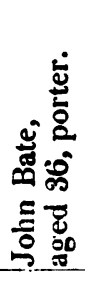 & 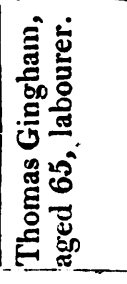 & 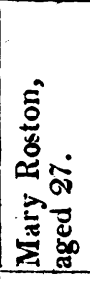 & 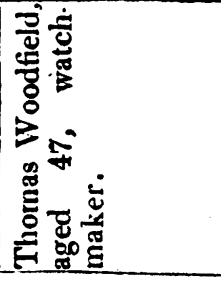 & 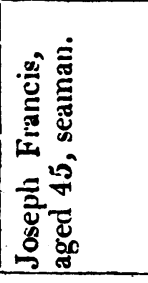 \\
\hline$\stackrel{\dot{Z}}{z}$ & 으 & $\equiv$ & $\stackrel{Q}{\sim}$ & $\stackrel{2}{\longrightarrow}$ & \pm & 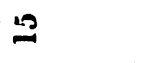 \\
\hline
\end{tabular}




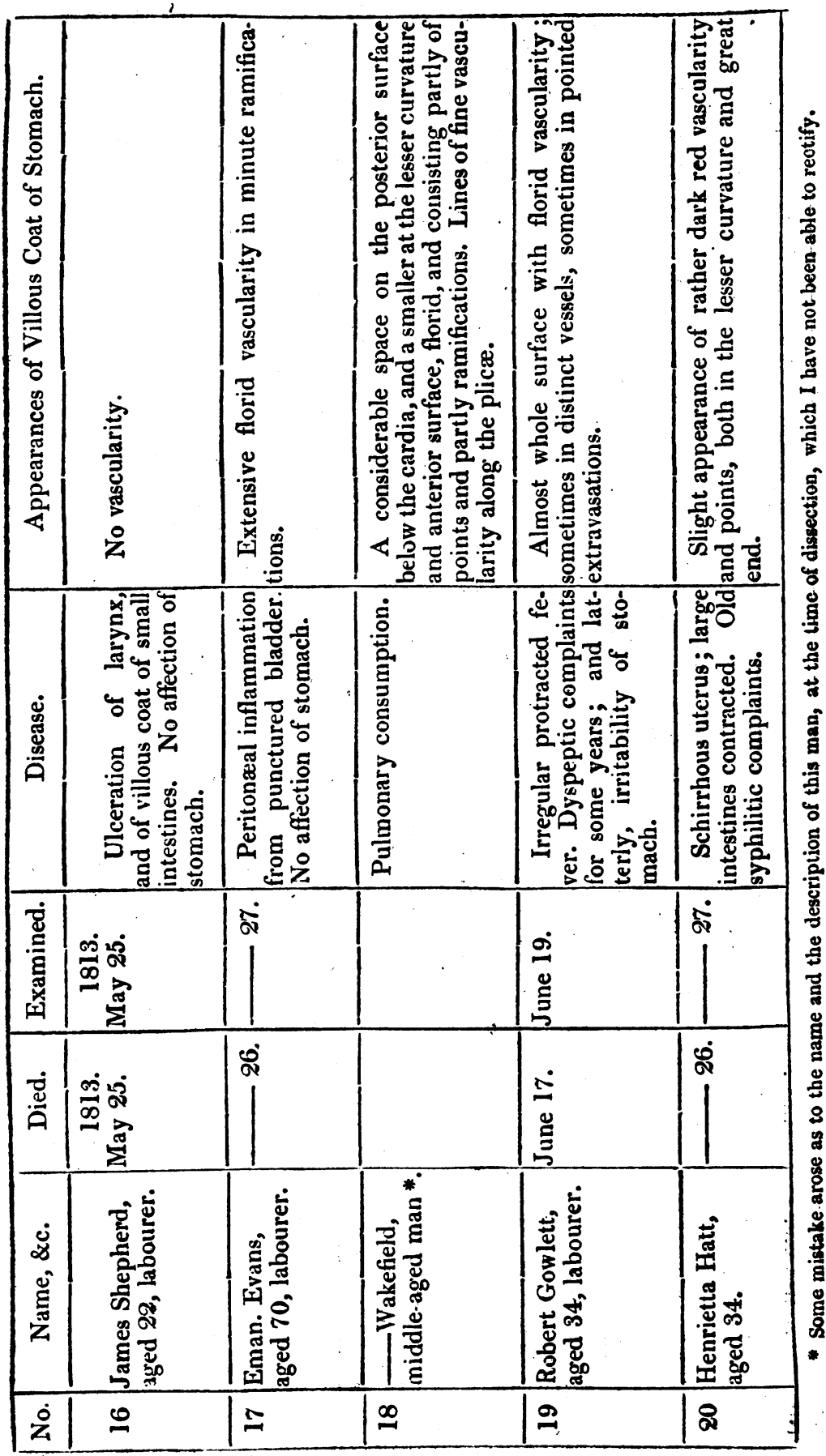


Before I make any remarks on the cases which have been given, and the appearances which they offer, I shall proceed to lay before the Society a description of the state of the stomach in five malefactors, who suffered death for murder, and who, before their execution, were in good health*.

\section{CASE I.}

Philip Nicholson, a man of about 30 years of age, was executed at Penningden Heath, near Maidstone, on the 23d of August, 1813, at two o'clock in the afternoon. The body was taken to Bromley the same night, and was opened in my presence, and the stomach examined by me, on the following day, at 3 o'clock in the afternoon.

The whole of the abdominal viscera were loaded, as if by minute injection, with dark-coloured blood. Here and there, however, there were florid vessels, which were distinctly traceable into dark-coloured ones.

The stomach had its external vessels very turgid. It had no fluid contents ; but on inverting it, afțer

* I was indebted to the kindness and liberality of several professional friends, for the opportunity of these examinations. 
an incision was made in the anterior part, through the pylorus, the whole cavity was found lined with dark-coloured, clotted blood, which was pretty firmly attached to the villous coat and its mucus, and came off, but with some little difficulty, on putting the whole into water. Much of it, however, still continued to hang about the plicx, at the great end, though the other parts were freed. The plicæ were distinct over the whole stomach, but not much elevated. Where the blood was washed off, it discovered the whole surface of the villous coat of a red colour; dark, where a portion of the blood continied to adhere; but florid, where it had been separated. The florid appearance was produced by minute vessels, which were, in general, distinct; but here and there in points, and occasionally in apparent daubs, consisting of extravasations, more or less extensive, and when more closely examined by a glass, divided into smaller portions of extravasation. The vascularity was unequal, being sometimes in irregular lines, with small portions of the proper strawcoloured hue of the villous coat interposed. Where the straw colour was pretty well marked, (which was in very few places,) there were still seen appearances of faint, and minute vascularity, in the substance of the villous coat, which imparted a very obscure red tinge to the straw-coloured hue.

A drawing of the appearances which a small 
portion of the stomach exhibited, was made on the same day and accompanies this paper.

On dissecting off the villous coat, its inner surface was found to be covered with numerous vessels, which were connected with larger ones, and were traceable into the substance of the villous surface.

The stomach was reverted; and on examination the following day, it was found, in many places, to have lost the florid vascular appearance abovementioned, and to have become of a pretty uniform crimson hue. It was then put into rectified spirit; but in the course of a few hours, was deprived, not only of the slight remains of vascularity which it possessed, but altogether of its sanguineous hue, assuming a brown tint, which it stilf preserves*.

\section{CASE II.}

Charles Masureaux, a young French prisoner, was executed at Gillingham in Kent, on Monday the 23d of August, 1813, early in the forenoon.

* Nicholson was reported to have died unusually hard, and to have been greatly convulsed. Times Paper of Aug. 25.

VOL. IV.

C $\mathbf{C}$ 
The stomach was taken out on the Tuesday, was sent to me in London on the Wednesday evening, and was examined on the Thursday morning - - It had been tied up at both openings, and a portion of the contents left in it. It was transmitted in a jar, at my request, without spirit or other fluid put up with it.

The external surface was very vascular, and of a light purple hue.-There was a large spot near the pylorus, and another in the greater curvature, of a green colour, which extended through the whole substance of the stomach; but there was no diminished cohesion in these parts. The stomach contained about 3 or 4 oz. of bloody, thick, and somewhat frothy fluid. The whole of the villous coat (with the exception of the green spots, and some dark-coloured streaks, which answered nearly to the plicæ of the stomach,) was of a bright crimson colour. No vascular appearance was perceptible in any part of the stomach, except in one spot near the pylorus, and in another in the lesser curvature, near the cardia, where a distinct portion of vascularity was seen at the extremity of the villous coat. Very obscure vessels were observable between the villous and muscular coats, on dissecting off the former, at various places. 


\section{CASE III.}

William Cornwall, aged about 25, was executed at Woodford, at 11 o'clock in the forenoon, of Monday, the 9th of August, 1813. The body was conveyed to town on the same day; and was opened in my presence, and the stomach examined by me, at half past two o'clock on the following afternoon.

The whole surface of the body, (but particularly the lower extremities,) had on it numerous small vesications in the form of wheals, without redness, of about an inch and a half in length, and a tenth of an inch in width.

The large veins, on the external surface of the stomach, were most of them moderately distended with blood, and the ramifications went to considerable minuteness, and were most apparent in the smaller curvature. The whole of the intestinal canal was minutely injected with blood, which was, for the most part, of a dark crimson, or purple, but here and there, of a florid hue.

The stomach had no remains of food in it; but it contained much thick mucus, which adhered to c c 2 
the whole inner coat. There were florid patches of vascularity in various parts of the whole inner surface of the stomach; which were most remarkable in the posterior part, towards the left side, and in the lesser curvature, for about two inches from the cardia. The general character of the vascular appearance, was similar to that mentioned in the case of Nicholson.

\section{CASE IV.}

John Denton, aged 45, was executed at the Old Bailey, on Monday Sept. 20, 1813, at eight o'clock in the forenoon, and was opened in my presence, and the stomach examined by me, at twelve o'clock at noon of the same day.

The small intestines were very vascular, but the colon was free from any appearance of vessels; and the stomach was not unusually vascular in its external surface. There was a strong contraction, at about one third of the distance between the pylorus and the left extremity of the stomach, making a very well marked separation between the pyloric and cardiac portions. Several ounces of coffee-coloured fluid, were found in the stomach. Plicæ were diffused over every part of its inner. surface, except for about an inch and a half round 
the cardia : they were very much contracted at the place mentioned as separating the pyloric and cardiac portions.

The colour of the villous coat throughout, was of a light crimson, varying slightly, however, in degree of brightness; sometimes being almost florid, and sometimes rather dark. Here and there, portions of a light straw colour occurred in streaks; but in these streaks very minute vascularity might be discovered by the naked eye, and better by a glass. The redness consisted of minute vessels; which rose up nearly to the surface of the villous coat, and diverged in still smaller branches, ending sometimes in a minute point, as if of extravasation, which was rather darker than the vessels, but incapable of being wiped off.

In a very few places, there lay attached to the villous coat, with mucus adhering to it, a small portion of blood, which, with the mucus, easily separated, and left beneath, a slight appearance of vascularity, but not more considerable than in most other places. A similar deposit of a portion of blood, occurred, in a slight degree, in a small portion of the duodenum which was removed with the stomach; but here the vessels were more continuous, and eotd be more readily traced along the villous coat. No difference of appearance occurred! between the anterior a postefior part of the stomach. 


\section{CASE V.}

James Leary, aged 42, was executed at the Old Bailey on Monday, Sẹpt. 20, 1813, at $80^{\prime}$ clock in the forenoon, and the stomach was examined by me, the following morning, at half past 11. About an ounce of thick dark-coloured mucus was found in it, which barely gave a red colour to water. Its inner surface was every where covered with plicæ, except for a short space around the cardia, and the whole presented an irregular mixture of strawcoloured and red lines; the red lines, for the most part, at the extremity of the plicæ, but not regularly so. The colour was generally of a florid hue, except where it dipped down between the plicæ; and there it was crimson. Around the pylorus, there was an irregular ring; of about an inch in width, of more continued vascularity. The redness was sometimes in the form of distinct vessels, and sometimes of extravasated points ; but the vascularity was less minute than in the case of Denton, and had more the character of that of Nicholson. The colour of the whole was much darker on the Wednesday morning.

From the statements which I have given, it may, I think, be fairly inferred, that, in the villous 
coat of the stomach, appearances of vascular fullness, whether florid or dark-coloured, in distinct vessels, or in extravasations of various sizes, are not to be regarded as unequivocal marks of disease. They occur in every variety of degree and character, under every circumstance of previous indispotion, and in situations where the most healthy aspect of an organ might be fairly expected. They are found in every part of the stomach, but principally in the posterior part of the great end, and in the lesser curvature; and they cover spaces of various extent, but are generally well defined, and terminate abruptly. - These circumstances have been confirmed by a great number of other examinations, which I have, at various times, had occasion to make; and I am inclined to think, that the first series of cases, may therefore be regarded as a fair average of the appearances seen in the adult human stomach. In young subjects, I should imagine, there is in general little vascularity seen after death ; for in the 16th case*, (that of a young man of 22,) there was none apparent; and of the bodies of two boys, which I have since examined, one, where death was produced by an abscess, exhibited a very obscure portion; and the other, where the cause of death was a fracture of the occipital bone, shewed nonet.

* In the last case, the whole surface of the small intestines was covered with small florid vessels, generally giving the appearance of small transverse parallel streaks.

$f$ Vide Table, p. 382 . 
Two coloured drawings of the appearances of vascularity, which were assumed in two cases which came under my view, are annexed to this communication.

The appearances which I have described, preserve their distinctness for a short time only, being best marked on the first day, and soon after, but at irregular periods, becoming more obscurē; the parts which were vascular acquiring a dark red, or purple tinge, which loses itself gradually. This effect more readily takes place when the villous coat is in contact with a fluid, particularly water. They exist in the body of the villous coat, and in general appear to be greatest, where that membrane is the least firm and resisting. Careful dissection discovers a fine net-work of veins between the villous and the muscular coat, from which the minute vascularity of the former evidently proceeds. This is very often capable of being traced, through the semi-transparent mucous coat, into larger veins beneath, by gently stretching the mucous coat, so as to render it thinner. The arteries are always empty, or very nearly so.

The vascularity now mentioned, often possesses a starred appearance, from the circumstance of its spreading in minute vessels, continually ramifying into smaller ones, to very near the extremity of the villous surface. A slight degree of friction, with the point of a scalpel, will open the minute extre- 
mities of the vessels; but I have never observed, that even by squeezing the larger branches, in a retrograde way, effusion into the cavity of the stomach could be produced, so as to stain a white substance which might be applied to the villous surface.

An appearance, very similar to the vascularity now described, is easily produced by injecting the veins (when there happens to be but little blood in them) with red-coloured injection; in which case, the villous coat, to the naked eye, but still more when a magnifying glass of moderate power is employed, exhibits a branched, or slightly stellated form of vessels, so descriptive of those which are seen in the human stomach*. If the veins, when injected, contain blood, the blood is forced, by the injection, into more remote branches, and at last escapes by rupture.-An appearance, a good deal like this, also takes place by injecting the arteries; but the vascularity now mentioned can be completely imitated, by forcing back with the finger, or the back of a scalpel, the

* Isinglass, or calves foot jelly, rubbed up with a proper quantity of colouring material, was the injection employed. It was thrown in through a pipe fixed on the coronary artery or vein, by a syringe, which contained about an ounce. The'stomach was inverted, the pyloric extremity tied, and the pipe brought out at the cardia, which was slightly enlarged, if necessary, and a ligature (as far as the pipes would admit,) placed on it. By this means, the flowing of the injection through the villous coat was kept under view. 
blood from the larger branches of veins into the smaller ones, by which means a species of minute injection into the very extremity of the villous coat, most readily takes place. Where a few larger veins have been apparent, this effect can be produced without the least extravasation, to a considerable extent; more particularly when the coats are thin.

I have never been able to produce, satisfactorily, a passage of injection from the artery to the vein, either in the stomach or intestines. The termination of the artery in the vein, must be very remote in the villous covering; for when these vessels are filled by injections of different colours, they are found to run, side by side, as far as they are capable of being traced.

There is a very remarkable similarity in the appearances exhibited in the stomachs of each of the malefactors, whose cases are mentioned above; and a general resemblance apparent between them, and the stomachs of persons who have died of natural death. In the former, however, the vascular character is more universal, and more vivid; and there is, besides, a disposition to effusion of blood into the cavity of the stomach, which does not occur in the latter. These differences may readily be accounted for, by the circumstances in which the vascular system is placed, before the total cessation of life, in persons who die by 
hanging; for in them, the usual disposition to vascular fullness in the stomach, is increased by the loading of the venous system, which occurs in consequence of the difficult transmission of blood, from the right side of the heart, during suspension.

In considering the state of an organ after death, with reference to the circumstances under which it may have appeared during life, it is necessary to consider, that in the latter case, both systems of vessels are filled with blood; while, in the former, blood is found in the veins only, the arteries being nearly, if not entirely empty*. It is likewise important to remark, that it is not from injections, that we can form any opinion as to the colour of parts, or the state of their circulation during life. Coarse injections will fill only large vessels; while fine injections will exhibit those which, like the vessels of the eye, are incapable, from their minuteness, of conveying red blood in the healthy subject. There is, besides, a considerable difference between the uniform colour of a living part, where the finest glass can discover no separation of vessels,

* __ " et a morte semper, arteriæ magis et magis inaniuntur, furtim et sensim, donec penitus albæ, et absque vestigio sanguinis sint, unaque cum membranis mesenterii pelluceant, a quibus non facillime distinguuntur.? Hallen's Opera Minora, tom. I. p. 200.

If any blood were contained in the minute arteries, it would be extravasated in injecting them, which I have never seen to occur with the arteries of the stomach, though it sometimes happens, as I have already stated, with the veins. 
and the vascular distinctness produced by injection.

These circumstances apply strongly to any deductions which we may endeavour to make, as to the usual state of the mucous coat of the stomach during life, from its appearance after death. It is, indeed, extremely difficult to form an adequate conclusion as to this point, and authors have given various opinions relative to it. By some it has been stated to be white * ; by others to be reddisht; by others to be greyish, bordering upon yellow and red $\ddagger$; clay-coloured or reddish $\varsigma$; or strongly marked red $\|$.

I have frequently seen the human stomach soon after death, and in such parts of it as were free from vascularity; it had usually a light straw-coloured tinge $\mathbb{T}$ : but, from the analogy of the mucous covering of the mouth and fauces, and of

- Dumas, Principes de Physiologie, tom. iv. p. 241.

† Cuvier's Leçons d'Anatomie comparée, tom. iii. p. 353.

¥ Boyrz's Traité complet d'Anatomie, tom. iv. p. 33\%.

§ Sogmmering de corporis humani fabrica, tom. vi. p. 220.

\| Bichat, Traité des Membranes, p. 44.

II In dogs which have been hung, I have seen it with a slight crimson blush nearly over its whole surface, which is most apparent at the plices, and seems to consist of minute crimson points formed as if by the projection of minute straw-coloured villi on a red surface. This appearance, I apprehend, is in some degree dependent on the mode of death. In pigs, I have always seen it of a light straw colour, with a slight crimson blush over a part of its surface. 
the urethra, it is probable, that when circulation is going on in the stomach, its inner surface is of a pale red hue, arising from vessels so minute as to give an uniform colour, without any appearance of distinct vascularity*. After death, the arteries and minuter veins are almost wholly emptied of their contents, and thus the colour of the villous coat is removed; but by dissection it will generally be found, that fine vessels are discoverable in the cellular membrane, which is interposed between the villous coat and the muscular. The removal of the colour, if we may judge from the analogy of the mucous membrane of the mouth, takes place very speedily.

It is difficult to ascertain in what way vascular appearances, such as those described by me, originate. That they take place about the close of life, is highly probable; but I feel myself unable satisfactorily to account for the mode in which they are produced. They are 'wholly venous, as is also the vascularity seen in many other parts of the body after death; the arteries, to which the veins which are so distended correspond, being

* The colour of the villous coat of the stomach and intestines is much alike in the dead body; being in both a light straw colour. Bichat states -generally, that the natural appearance of the former, (meaning of course in the living body,) is a strongly marked red; and he gives an instance of a wounded and inverted portion of intestine, in which there was the redness, 'qui caracterise cette surface dans l'etat naturel.' 
generally empty. It would therefore appear, that there is a power capable of being exercised in the artery itself, which carries on the blood to the capillaries, or to the veins, after the further supply of fresh blood from the heart is stopped; and that there is thus a species of accumulation produced in the veins, which is adequate to the production of the phænomena in question *.

In men who have been hanged, there is an obvious cause of accumulation in the veins; and the same cause seems to act, in a smaller degree, in cases of ordinary death. It operates also, in death by drowning; but I have had no opportunity of ascertaining whether, in this case, the same appearance of stomach is produced, as in suspension. The striking vascularity so often observable in that organ after death, in consequence of venous accumulation, seems to be, in a great measure, referable to the peculiar laxity of the medium in which its blood vessels are placed, and to the great number with which it is supplied. Hence, likewise, the disposition which it exhibits to effusion of blood, as well during life as in death from suspension.

* Etenim ubi cor sanguinem allatum in arterias promovere non amplius valet, illa vis (elastica) ad urgentem in venas sanguinem sufficit. At si vis ista elastica simul cum vita perditus v. c. arteria in os mutatur, arteria quoque post mortem sanguine plena conspicitur.'

Semmering De Corporis Humani Fabrica, tom. v. p. 64. 
The different degrees of colour, from dark purple to florid, which I have noticed as being seen in the vessels of the villous coat of the stomach, appear likewise occasionally in the veins of the mesentery and intestines. They afford examples of arterial hue, or a certain portion of it, continuing in blood, some time after the reflection of an artery into a vein. There are many facts which prove, that this change of arterial into venous blood may, under some circumstances, be accelerated or retarded in the living body; and $\mathrm{Mr}$. Hunter has observed, that there is generally a palpable difference in the degree of darkness of venous blood, taken at different distances from its source in the arteries; for instance, at the hand, and the bend of the arm*.

The precise circumstances under which arterial colour is preserved after death, are not altogether known. The florid hue seems to be an exception to that in which blood usually appears in the dead body; for there the arteries, (when they are not empty) as well as the veins, contain dark blood. This change from the proper colour of the blood contained in the arteries, is supposed, by $\mathrm{M}$. Bichat $t$, to take place before death; for he is of opinion, that in most instances, for some little time previously to the extinction of life, the whole of

* Hunter's Treatise on the Blood, Inflammation and Gun-ohot Wounds, p. 69.

† Anatomie Générale, tom. ii. 
the blood which circulates through the body, is dark; and that, where any surface after death is found to be florid, (and he instances the mucous membrane of the nasal fossæ as being occasionally so,) it has continued in that state by means of its capillaries, which the conceives are not easily affected by changes which may have taken place in the circulation of larger vessels.

This conclusion, with regard to the capillaries, would merely provide for their continuance in the state in which they existed during life; but it is hardly reconcileable with the enlargement which, after death, is so palpably seen to have taken place in them, in the human stomach. Such enlargement can scarcely have been produced, except by a force sufficient to overcome the resistance made by the parietes of these minute vessels to the augmentation of blood ; and for this force, it is difficult to look except to the arteries; particularly as those of middle and smaller size are, after death, found to be freed from blood. In this case, however, the blood last projected, might, if dark, have been expected to impart to such capillaries, a dark, instead of a light colour; which in many instances, it has been seen, is not the fact.

The change from forid to dark coloured, or from dark to darker red, which, as I have ob served, takes place in the colour of the minute vessels of the stomach, in the course of a short 
time, is in some degree analogous to that change, which Mr. Hunter has observed to occur, by rest, in the colour of arterial blood, whether contained in aneurismal sacs, in cellular membrane in consequence of extravasation from wounded arteries, or in the brain after apoplexy*.

The diffused redness, to which I have stated that the distinct vascularity of the villous coat soon gives place, occurs in a longer or shorter time, without any obvious cause for such difference. It seems to be the effect of transudation from the coats of the containing vessels; for I have seen, on inverting a vascular stomach, extending it upon a flat surface, and keeping it moist and undisturbed, that a blush is communicated from both larger and smaller veins to the contiguous cellular' membrane, which very gradually increases in extent: while such parts of the villous coat as possess minute vascularity, lose it under such circumstances; the interstices becoming coloured by the transuding fluid, so as to give the whole of the surface an uniform crimson or purple tinge. The effect mentioned, I have observed to commence, in a recent stomach, in the course of a day, or a day and half, but sooner in one which is less recent though not at all putrid. Putrefaction will doubtless increase, but it does not seem at all necessary to transudation.-This diffusion of co-

* Hunter, l.c. p. 65.

VOL. IV.

D D 
lour is, therefore, analagous to the transudation of the bile from the gall-bladder, which is so very generally observed in the examination of bodies*.

The slight resistance which dead matter is able to give to a contained fluid, is proved (if more proof than what the gall-bladder affords is necessary) by the employment of any two fluids, which are nice tests of the presence of each other. Thus, in a portion of inflated recent intestine, when the mesenteric arteries are carefully injected with solution of prussiat of pot-ash, and the veins with solution of green sulphat of iron, no effect is perceptible for a short period; but very soon the blue colour is produced, in the whole course of both systems of vessels, to considerable minuteness, and at the same time. If the carotid artery, or a portion of intestine (both of them recent) be filled with either of those fluids, and tied, and the centre be made to dip into a small vessel containing a portion of the other fluid, it becomes very speedily tinged with blue precipitate, at the place of contact.

\section{Are circumstances of vascularity affected by}

- Haller refers an appearance of transudation from the intestinal vessels of a female who died of erysipelas in the leg, to inflammation, though there is every reason to suppose that it occurred after death. " Intestina flatu insigniter distenta, tota inflammata erant, non quod vascula unice distenderentur, sed quod cruor secundum totam longitudinem arbuscularum vasculosarum in cellulositatem effusus, lineam obscure rubentem, in vasis circumpositam efficeret."-Opera minora, tom. iii. p. 349, obs. 53. 
thinness of coats ?-The coats of the stomach vary very much in thickness in their different parts; the whole substance being sometimes so thin at the great end, as readily to admit of making out through it, dark figures on a light surface. In one case of this kind, the weight of two oval portions of similar size varied about three fourths : the portion taken from the fundus amounting to $5 \frac{I}{8}$ grains, while that taken from a part about midway to the pylorus (where this stomach seemed to be thickest) amounted to $22 \frac{1}{4}$ grains. This stomach admitted the injection of its arteries close to the part where a ligature had been placed round the oval orifice, without extravasation; and another stomach allowed the injection to pass, with the same success, over a portion, which, to judge by figures seen through it, was equally thin.

The veins, likewise, when pressed backwards, minutely injected their smaller branches, just as has been described to take place, in ordinary circumstances of venous turgescence, without any effusion being produced into the cavity of the stomach ; for the blood, in the minutest extremities of these vessels, was incapable of being wiped off, or of giving any tinge to a white surface applied to the villous coat in which they terminated. This last mentioned circumstance, I have likewise frequently remarked, in cases where the great end of the stomach was nearly as thin, as in the stomachs above mentioned, if not equally so. Where there 
was, however, the slightest cut in the villous surface, the vessels were divided, and consequently effusion took place.

The difference of thickness which occurs between different parts of the same stomach, is produced by variations both in its villous and muscular coats ; for I found that of two equal oval por-. tions of the same stomach, one of which was taken at the great end, and the other near the pylorus, in the lesser curvature, the former weighing six grains, had its villous coat consisting of $2 \frac{1}{2}$ grains, and the peritoneal and muscular together of $3 \frac{1}{2}$ grains; while the latter, weighing $19 \frac{1}{2}$ grains, had its villous coat consisting of seven grains, and its peritoneal and muscular together, of $12 \frac{1}{2}$ grains *. The thickness of the peritoneal coat appears to be pretty uniform ; but that of the muscular and villous to vary, not only in different stomachs, and in different parts of the same stomach; but in relative proportion in such different parts.

* It may be proper to mention, that the weight of the villous, and of the peritoneal and muscular coats of nine similar oval portions of this stomach, was taken with some care, the dissection being made after separation from the stomach. In three other similar portions, the peritoneal and muscular coats alone were taken, the villous having been dissected off previously to removal. The following are the weights in grains, viz.

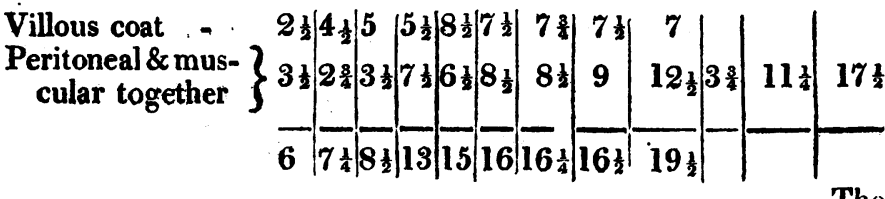

The 
Mr. Hunter, in his valuable paper on digestion after death, makes some observations relative to the great end of the stomach, to which, as being intimately connected with the subject of this paper, it is necessary that I should advert.

"There are few dead bodies," he remarks, " in " which the stomach, at its. great end, is not in "s some degree digested ; and one who is acquaint" ed with dissections, will easily trace these gra" dations. To be sensible of this effect, nothing " more is necessary than to compare the inner "s surface of the great end of the stomach, with " any other part of its inner surface; the sound " portions will appear soft, spongy, and granu"c lated, and without distinct blood-vessels, opake " and thick; while the others will appear smooth, "s thin, and more transparent ; and the vessels will sc be seen, ramifying in its substance; and upon

The thinnest portions were from the great end, the others from different other parts of the stomach, but the thickest were taken near the pylorus, particularly the heaviest portion $\left(17 \frac{1}{2}\right)$. The mucous coat had been dissected from this portion before it was taken out, so that the united weight was not known; but it could not be less than twenty-four grains.-It is obvious that there are various sources of error in ascertaining, very correctly, the weight of such soft and yielding parts which are to be separated in equal portions. That there is a considerable difference in the quantity and proportion of each coat, in different parts of the same stomach, seems to be all that it is of any consequence to know.

I should imagine that it is but seldom there is so much disparity between the thickness of different portions of the same sto. mach. The great end is not unfrequently extremely thin. 
"squeezing the blood which they contain, from " the larger branches to the smaller, it will be " found to pass out at the digested ends of the "vessels, and to appear like drops on the inner "surface*." These effects, he attributes to digestion, by the gastric juice, in the ducts of the glands which secrete it.

With every respect for the high authority of a gentleman to whom the professional world is so much indebted, I shall state to the society, the circumstances in which my own observations have not agreed with those of Mr. Hunter, as to some of the points mentioned in the quotation just given.

The great end of the stomach certainly appears, in general, to be smoother, thinner, and more transparent than the other parts; but its thinness does not apply to the villous coat alone; there is also, (as I have already shewn,) a very great thinness of the muscular coat, at this place, which may equal, and sometimes exceed that of the former.

The instances which I have mentioned above, afford striking examples of thinness in the coats of the stomach at its great end; but that this thinness

* Hunter's Observations on certain Parts of the Animal CEconomy, p. 226. 
originated in erosion of the villous coat by the gastric juice, appears to me to be very doubtful; because it is difficult to conceive, how this effect could occur without being accompanied by an erosion of the ends of the arteries, and consequent extravasation on attempting to inject them : but yet in the cases which I have stated, where the substance of the stomach was in the extreme of thinness, no extravasation took place when the arteries were injected. In those cases likewise, the venous blood, on forcing it backwards, filled minute vessels, but was not extravasated.

I can hardly indeed conceive, that if the great end of the stomach were, in ordinary circumstances, eroded by the powers of the gastric juice, we should be able, with any degree of certainty (as we assuredly are), to fill its.vessels by injection; unless we could suppose, that the vessels were left unaffected in the solvent operation. Mr. Hunter was quite aware that the gastric juice, in diminishing the thickness of the villous coat, must digest the ends of vessels; for he gives as a proof of digestion of the stomach taking place, that blood, when forced from larger branches into smaller ones, passed out at the digested ends of'vessels, and appeared like drops on the inner surface. Such a degree of digestion, however, must, I venture to suggest, be very rare; for in the many trials which I have made as to this point, particularly where the stomach was exceedingly thin, it has never hap- 
pened to me to be able to do more, than fill the minute extremities of the veins, (in the way which I have already mentioned) by pressing the blood backwards in the larger branches. These minute extremities are easily ruptured, in injecting the veins; and if a sufficient body of blood could be forced back from the trunks into them, (which can scarcely be the case) it is most likely that the same effect would follow.

Mr. Hunter seems to refer the vascular appearance, seen in the inner surface of the stomach, to thinness of the villous coat; meaning, I presume, to imply that the vessels are generally in a state to be visible, provided a certain portion of the villous surface by which they.are covered, or in which they are imbedded, were removed from them. This, however, does not appear to me to be the case; for the visibility of vessels, as far as I am able to judge, arises, in a considerable degree, from the accidental circumstance of blood being contained in them, without which, they would be difficultly seen at all.* ; and the possession of blood, seems to me to

* The term vessels, employed by Mr. Hunter, can only apply to veins, the arteries being always empty, except perhaps in a portion of their trunks. If blood is not contained in the veins of the stomach, even the trunks of those veins are discovered with very great difficulty. The arteries may generally be traced by their size, while they run between the peritoneal and muscular coats, which is the first part of their course in the stomach; but in the small branches, they are seldom, in their usual state, to be seen or felt. 
be in a great degree independent of the state of the coats as to thickness.

It by no means follows, because large veins are frequently seen ramnifying under the villous coat of the great end of the stomach, (when this is thin, and therefore admits them to be seen through it,) that a similar vascular appearance will be seen in other parts of that viscus, by dissecting off the whole, or a part only of the mucous coat which lines it.

The nature of that vascularity which is so generally seen in the villous coat of the stomach, seems to have been very much misunderstood among authors, even of high eminence.

Hoffmann has a chapter entitled, "de inflam" matione ventriculi frequentissima," in which he expresses his surprise, that a complaint so common, as he found inflammation of the stomach to be, should have been so little observed; and he points out as indications of this disease, appearances very similar to such as are mentioned in this paper, to be of usual occurrence*. He admits the existence of similar appearances, in plague and various fevers; but in the former, he attributes their occur-

* “In corporibus dissectis, ventriculus valde rubicundus, variis modo rubris, modo nigris maculis distinctus, vasaque sanguinea et capillaria multo sanguine turgida reperiuntur; quandoque orificium sinistrum macula lata nigra notatum visitur." "Non totis vero ventriculus semper, sed pars saltem, maximè vero fundus, inflammatur." Hofrmanni Opera, tom. 6. p. 224. 
rence to a species of poisonous miasma, inhaled by the breath, which produces spasm, and by this means, inflammation of the stomach. '

De $\mathrm{H}_{\text {AEN }}$ * and Stoll $\dagger$ give examples of what they regard to be inflammation of the stomach, terminating in gangrene, without having exhibited any of the usual symptoms of gastritis; and the former recommends this occurrence, as a very remarkable and puzzling one, to be added to his chapter of Problemata et Difficultates.

Selle, in his Pyretologia $\ddagger$, refers to De Haen, as affording a modification of the usual definitions of gastritis; and Cullen seems also to have depended on the authority of the same author, when he states, "that it appears from dissections, that the " stomach has often been affected with inflamma«s tion, when neither pain nor pyrexia had before " given any notice of it $\$ . "$

* " Nec minus mirabilis ventriculi, et obstructi, et perquam inflammati, et gangrænosi, contemplatio, ubi ad mortem ferè usque, nec signa febris, aut gangrænæ in pulsu, nec signa doloris in hoc viscere, nec signa alicujus in ejusdem functione defectus, apparuerint." DE HAEN's Ratio Medendi, pars 6, cap. 12. § 2.

+ - ventriculus ingens" — cujus posterior facies longè latèque ex inflammatione"_- rubebat"___ "En hio quoque ventriculum inflammatum, absque consuetis et manifestioribus inflammationis signis. Intestina livida, vel absque, prægressa inflammatione fuerunt, vel prægressa est inflammatio absque ejusdem signis."' Stols's Ratio Medendi, tom., 3, p. 380.

$\ddagger$ SEl.Le's Rudimenta Pyretologiæ Methodicæ, p. 139.

$\S$ Cullen's First Lines of the Practice of Physic, vol. i. p. 420. 
Portal, in speaking of the great vascularity of the stomach, says, that by means of the slightest turgescence of the vessels of the stomach, particularly the veins, the villous coat becomes dark; an effect so common, that this black colour ought to be regarded as a marle of inflammation, rather than poison*.

Frank states the frequency of inflammation of the stomach, and enumerates its symptoms: but he admits, that in many instances, where inflammation was found in the stomach after death, most of those symptoms were absent; in others, where the greater part of the symptoms were present, that no mark of inflammation was to be discovered on dissection; and in others, that a similar train of symptoms was removed, by means which were adverse to inflammatory complaintst.-I am like-

* Portal's Cours d'Anatomie Medicale, tom. 5, p. 164. He adds, " Dans quelques cadavres, on ne trouve ce viscere inflammé, que dans quelques points, comme vers le cardia, vers le pylore, souvent dans la grande courbure de ce viscere, ou ailleurs; d'autrefois les parois de l'estomac sont inflammées dans toute leur etendue. Tom. 5, p. 194.

$\dagger$ “ Non infrequens stomachi humani morbus est gastritis, aut ejusdem inflammatio; cujus quidem signa principalia in febre acuta, in epigastrii tensione, ardore, dolore, in vomituritione, anxietate, singultu, ab assumptis quibusvis mox, et cum subitanea istorum rejectione, adauctis consistunt: sed in multis, qui ventriculi post mortem phlogosin obtulere, nunc plurima ex istis defuerunt; nunc, cum pars major symptomatum in xgrotante comparuisset, vel in cadavere infl ammationis ad ven- 
wise inclined to think, that vascularity of, and extravasation into, the villous coat of the stomach, as well as external vascularity of the intestines, particularly when these appearances are dark-coloured, have been occasionally described as inflammation or gangrene, even by Morgagni and Lieutaud, two of the highest authorities in pathology *.

HaLler also seems to regard fulness of vessels as a proof of inflammation; for he states, that he has so often, in his dissections, seen inflammation of the intestines present, as to consider such an affection as almost constant in every kind of fever,

triculum in vanum quærebantur vestigia; vel ab aliis causis dictorum ffectuum pependerat cohors, ac a medendi methodo, inflammationis certe contraria, potuit dissipari."-Frank (J.P.) De curandis hominum morbis epitome, lib. 2. p. 253.

* "Ventriculi fundus atro colore;" "ventriculus intus inflammatus, minimisque vasculis multum sanguine turgentibus;" " ex atro (ilii partes) rubebant, sanguiferis vasis, non secus ac post injectam coloratam ceram, manifestissimis," are examples of the mode of description frequent in Morgagni's valuable work.In one instance, (epist. 29. art. 29.) the absence of pain in inflammation of the bowels, is attributed to a paralytic affection, which took off the sensibility of the parts; and from other cases Morgagni deduces the inference, that pain and fever are not necessary for the existence of inflammation of the intestines. His words are, (epist. 35. art. 21.) " Nec tamen, siquando alterum vel utrumque horum"' (nempe yehementem dolorem, vel acutam febrem) " aut abesse, aut vix esse invenies, continuò putabis, aut nullam esse inflammationem, aut levem, aut gangrænam et sphacelum in eorum esse intestinis non posse, in quibus duo illa pracessisse non videris." 
and frequent in every other complaint *. Numerous examples of the same opinion are to be found in other respectable authors.

The importance of distinguishing between darkness of colour, and proper inflammation, or its effects, was noticed at a very early period by $\mathrm{H}_{A-}$ BICoT, a French surgeon of eminence in his time, who states, that persons are often deceived into a belief, that the dark colour produced by the gastroepiploic vein, in the greater curvature of the stomach, is the effect of poison $t$.

* Haller's Elementa Physiologiæ, tom. 7, p. 43.

Most of the cases of inflamed stomach noticed by Lreutaud, are taken from other authors. One of them (Historia Anatomica Medica, tom. i. p. 26, obs. 68.) is abridged from HALLRR's Opera Minora, tom. 3, p. 295, and seems to me to shew how loosely inflammation of the stomach has been put down among diseased appearances. It is the case of a person, in whom, though there had been no affection of the stomach during life, that organ was found, on examination, to be universally inflamed, and blood effused into some parts of its cellular substance. The patient was a man of 50, who had recovered from an attack of pleurisy, but remained very liable to pectoral complaints. From exposure to cold, he was seized with a violent fever, with pain and oppression in the chest, which were followed by hiccup, delirium on the 8th day, and death on the 12th.-See some judicious observations on the differences between inflammation and vascular fulness in membranes, in Hunter on the Blood, p. 281.

† “ La partie interieure d'iceluy vētricule estāt netloyée demōstrerez, tant la tunique interne qui est veloutee, \& comme l'abontissemēt qui se faict des vaisseaux provenās de la vene gastre epiploique en la partie gibbe dudict ventricule, le rend de couleur noirastre, qui a faict croire à beaucoup d'inexpers, en la me- 
The means of forming a satisfactory conclusion in cases of suspected poison, obviously connect themselves with the proofs, which dissection is capable of affording, of the existence of inflammation in the stomach during life. There are no circumstances under which medical men have a more serious and anxious responsibility, than in the examinations which they are called upon to make in such description of cases; for while, on the one hand, public justice demands from them an unequivocal avowal of the results of their judgment and experience, for the conviction of guilt ; it is equally required, that their opinions should be founded on an accurate knowledge of what are the effects of natural causes on the human body, and what the consequences of deleterious operation. The most able and experienced men have found difficulties in making up their minds as to the necessary effects of poisons ; and it would be highly important, both for the interests of the public, and the credit of the profession, that the means should be afforded of directing the judgment, in those de-

dicine \& chirurgie, aux maladies violentes y avoir eu poison ou venosité en leur mort."- tique Anatomique, p. 4ุ, leçon 3, Paris 1610.

BOYER makes nearly a similar remark: "Le grand nombre de vaisseaux qui se distribuent dañs cette tunique (la veloutée) lui donne souvent une couleur pourpré obscur; c'est a quoi il faut faire la plus grande attention lorsqu'on est chargé de faire l'examen des corps de personnes que l'on soupçonne mortes de poison."-Traité complet d'anatomie, tom. 4, p. 337 . 
licate and difficult problems, on which medical testimony is occasionally required in courts of justice*.

Authors on Forensic medicine have been too apt to generalize, without having had the benefit of studying, sufficiently, individual cases; and hence the effects of putrefaction, and the spontaneous changes which the loss of vitality produces on the human body, have, in descriptions, it is to be feared, been sometimes misunderstood, and sometimes confounded with the proper and necessary operation of poisons.

Some of the most respectable writers on this subject, have represented the effects produced by poisons on the stomach, œsophagus and intestines, to consist in diminished cohesion, inflammation, mortification, erosion, and perforation of those organst: but later and more particular observa-

* I allude more particularly to the hesitation which Mr. HuNTER had, in the celebrated trial of CAPt. Donnellan, in distinguishing between the effects of poison, and the effects of putrefaction.

A report of this important trial was published by Mr. Gurney, at length, from the account taken by him in short hand. A full abstract is to be found in the Gentleman's Magazine for 1781, and in the London Chronicle for March of that year.

+ Mais ce qu'il y a de constant dans les cadavres des personnes qui ont péri d'un poison àcre ou caustique, c'est de trouver l'œsophage, l'estomac et les intestins grêles atténués enGlammés, gangrénes, rongés et souvent percés.

Maнon's Medicine Legale, tom. ii. p. 308. 
tion seems to evince, that the only morbid change which may be invariably expected, is inflammation; for the others are either occasional only in their occurrence, or equivocal in their nature; as in the case of mortification, or gangrene, which may be assumed to exist, from mere darkness of colour. Mortification and gangrene, are rare occurrences in either the stomach or the bowels; and they are not noticed by Dr. Baillie, in his Morbid Anatomy, as belonging to the usual effects of mineral poisons, nor by Mr. Brodie*, nor Dr. Jaegart, both of whom have attended very much to the operation of those substances.

Plenck, in his Toxicologia, page 13, says that we may distinguish when a person has been destroyed by poison, " si in tali cadavere ventriculus inflatus vel spasmodicè contractus, aut inflammatus, vel gangrænosus, vel saltem maculatus inveniatur, absque alia prægressi prius morbi causa."

Dr. Parr states, that when " stimulant poisons have been the cause of death, the abdomen is greatly inflated, becomes rapidly putrid, dark spots appear on the body, erosion, inflammation and gangrene are found in the fauces and stomach, the blood is black, and collected in the veins; above all, the villous coat of the stomach is destroyed."

Medical Dictionary, art. Medicina Forensis et Politica.

* Further experiments and observations on the action of poisons on the animal system.

Philosophical Transactions for 1812, part ii. p. 210.

+ Dissertatio Inauguralis de effectibus arsenici in varios organismos, necnon de indiciis quibusdam veneficii ab arsenici illati.

Edinburgh Medical and Surgical Journal, Jan. 1811, vol, vii. 
I may add, that in a case of poison by arsenic, which I saw some years ago, there was no diminution of natural tenacity, which is the only certain test of a part being mortified; and no circumstance from which gangrene could be inferred, but the very insufficient one of darkness of colour*.

Neither is the disposition to putrefy, in such cases, materially different (as is geneirally imagined) from what it is in ordinary circumstances : and that erosions very rarely happen, and are sometimes liable to be suspected, when they do not exist, is rendered probable, by the consideration of the facts brought forward by the two last named gentlemen.

But if it be admitted, that the only constant and necessary primary effect of mineral poisons on the human stomach, is the production of inflam. mation, it is important to inquire, whether such appearances of inflammation are so distinctly and unequivocally marked, as to be readily distin. guishable from mere vascular fullness, or slight extravasation, as described in this paper?

* Case published in the Edinburgh Medical and Surgical Journal for October, 1809. It is remarkable that in this case, there was reason to suppose, that the patient had suffered little or no pain, -and in the only example which Dr. JARGAR saw of death by arsenic, in the human subject, there was no complaint of pain, even when the patient was asked about it.

$$
\text { vol. IV. } \quad \text { E }
$$


To this question, I fear, that an answer, which is completely satisfactory, cannot at present be given.

Dr. BaIllie states, that in inflammation of the stomach, that organ is " a little thicker at the inflamed part, the inner membrane is very red, from the number of small florid vessels, and there are frequent spots of extravasated blood, which appearances are more intense, when arsenic has been swallowed." With this account, Mr. Brodie's observations, in considerable measure agree.

In a dog which had taken several grains of corrosive sublimate, and which was destroyed a few hours afterwards, for the purpose of observing what might be regarded as appearances of recent inflammation in its stomach, the following were the principal circumstances remarked *.

That part of the stomach which extended from the cardia, about an inch and a half along the lesser curvature, and about three parts of an inch in every other direction, together with a few other portions of a very small extent, possessed a pretty deep

* This dog I examined with Mr. Lawrence, Assistant Surgeon to St. Bartholomew's Hospital. The dog had vomited considerably. He was directed to be destroyed by a blow on the head, instead of by suspension, which would have affected the appearances, by producing unusual accumulation in the veins. 
crimson hue; while the pyloric portion was of a light straw colour, and the other parts of a greyish pink. The crimson colour, though deeper, had, in other respects, very much the character of what was mentioned in the note to page 396 ; but it was mixed with darker coloured patches, which seemed, on inspection, to consist of coagulated effusion, or coloured coagulum, in the substance of the villous coat, very similar to that which is sometimes found in an inflamed serous membrane, on which coagulable lymph had been very recently. deposited. The plicæ were numerous and firm; there was little external vascularity; and below the villous coat, there were some minute veins perceptible, (particularly where the coat was reddest) which could not however be traced into its substance.

Immersion in water removed part of the general redness; but that of the dark patches remained, with little change, till putrefaction commenced.

The villous coat of the intestines had occasional patches of light crimson efflorescence.

I thought that it might be agreeable to the Society for me to annex a coloured drawing of what seemed to be the effects of inflammation in a portion of the stomach of this dog, by. way of comparison with the healthy appearances before described. I have accordingly done so; but I can 
hardly offer this, either as an example of a well marked difference between mere vascularity and inflammation in a part; or as an instance of the appearance which inflammation would make in the human stomach ; because in the latter, the villous coat is much less firm, and therefore much more disposed to venous accumulation, than in the former. This is distinctly evinced by the difference which occurs between the stomach of any of the malefactors, whose cases are given above, and that of a dog which has been hanged. In the latter (as I have already observed) there is generally a very slight pink tinge only, over the whole inner surface, divisible however into minute points; while in the former, there are well defined vessels universally diffused.

It is highly important that appearances of inflammation in the stomach should be correctly distinguishable, after death, from those of mere vascular turgescence; but it does not appear to me, that the discrimination can at present be made with sufficient precision.-The following observations, I take the liberty to offer, as suggestions relative to this subject.

When the stomach is inflamed, coagulable kymph is occasionally thrown out in the substance of the villous cost; or upon its surface; and this, when it occurs, (which I believe to be but rarely the case) is perhaps one of the least equivo- 
cal indieations of previous inflammatory action. But thick mucus sometimes assumes a good deal the appearance of caagulable lymph; and the existence of a coloured coagulum, may occasionally be confounded with a coagulated portion of extravasated blood, adhering (as in the case of Nicholson) to the villous coat; which may the more readily occur, when the former is not in quantity, sufficiently great, to produce well marked thickening. It is also to be observed, that in eases where mineral poisons have been given, the deleterious operation (as appears from the experiments of Mr. Brodie) is generally upon the brain and nervous system; and in this case the inflam. mation produced on the stomach itself, may be short of that which would produce effusion of lymph.

It is exceedingly likely, that in inflammation of the stomach, the redness is less distinctly referable to vessels, and the florid colour more permanent, than in mere turgescence: but it is not to be forgotten, that it sometimes happens in eases of natural death, that the vascularity of that organ is partly florld and distinct, and partly diffused 3 circumstanees which may create a little embarrassment, when they are to be considered with referenoe to a certain supposed cause.

In every case of death from poison, the appear. ances which dissection may offer, must be modi- 
fied by the state of the blood-vessels after death, and by the very vascular nature of the stomach, and the disposition to accumulation in its veins, which occurs at the close of life. We may therefore not unreasonably expect such venous accumulation, to be often superadded to the proper and necessary effects of inflammation.

If well marked erosions were the frequent effects of severe inflammations, they would materially assist in forming a ground of discrimination. As Mr. Brodie and Dr. Jaegar, however, represent erosions to be very uncommon effects of arsenic, it is important that the frequent thinness of the fundus of the stomach, and the occasional inequalities of the villous coat, either there, or in other parts of that viscus, should not be mistaken for them. These inequalities are by no means unfrequent, and I have often seen them to a considerable degree, where they were unquestionably mere peculiarities of structure.

In judging of the existence of external inflammation in the living body, it is not by mere redness, or by turgescence of vessels, that the opinion is guided; but by those circumstances, in conjunction principally with pain, heat and swelling. It does not therefore appear to be less necessary, for the purpose of enabling us to judge of the existence of internal inflammation, that something unequivocal in the symptoms should be superadded to the 
appearances submitted to our consideration, than that there should be assistance required in judging of external affections, in addition to mere colour or. vascularity.

But on the subject of symptoms, it is important to recollect, not only that genuine gastritis is extremely rare, but that affections of some neighbouring parts, which may sympathize much with the stomach, may be confounded with original affections of the stomach itself. This organ, too, is liable to many very painful or uncomfortable sensations, which there is no reason to consider as marking it with any particular character of disease.

In offering these remarks, I may, perhaps, be regarded as having somewhat aggravated the difficulty of forming a judgment, after death, as to the existence of inflammation of the stomach during life. It does not appear to me, however, that I have done so; and I should be happy, if, by calling the attention of professional men to the subject, a more correct, and more practical diagnosis should be established, than is at present possessed, relative to the operation of inflammation in that organ, from whatever cause it may have proceeded.

Before I conclude this paper, it is necessary 
that I should advert to the appearances of inflammation, which are generally stated to be found in the stomachs of hydrophobic patients, and which have been, by many, thought to prove that hydrophobia is a species of gastritis.

I have seen five cases of hydrophobia, and have been present at the dissection of three of them; but I am unable to say, that there was any palpable difference, between the vascular appearance of the villous coat of the stomach in those cases, and that which is ordinarily seen, in the human subject, where there was no affection of the stomach during life.

In some of the cases which are upon record, the stomach is stated to have been entirely free from disease *; and most of the other examples to be found in authors, particularly those which are published in the Memoirs of the Royal Society of Medicine of Paris for 1783, and by Dr, Hunter, in the 1st volume of the Transactions of a Society for the Improvement of Medical and Chirurgical Knowledge, afford no appearances in that viscus, which are not referable to fullness of vessels only.

- See Vaughan's Cases and Observations on Hydrophobia, Cases 1st and 3d.-Also two cases by Dr. Babington, the first in Medical Communications, vol. I. p. 215; the second in Medical Records and Researches, p. 117; and several cases quoted in Hamilton's Work on Hydrophobia. 
The appearances observed in the stomach of the log, are rather more diversified. The principal number of cases reported, exhibit marks of redness and fullness, or slight extravasations of various extent, in the villous coat; but there are some mentioned, where this coat presented nothing morbid in its aspect *.

When we compare the descriptions given of the state of the stomach, in most of the cases of hy. drophobia recorded as occurring in the human subject (for I do not take into account any extraordinary, or anomalous cases) with the series of dissections presented in this paper, the resem. blances are striking, and certainly tend to throw some degree of doubt on the idea very commonly entertained, that the usual vascular appearance observed in hydrophobic stomachs, is inflammation; and that it is connected with the production of the symptoms which existed during life. It is very difficult to conceive, that the cause of one of the most formidable and distressing maladies of the human body, can be such an affection of a part, as is, in many cases, so slight, as not to be an object of attention or remark at all; and in most, does. not exceed what is very generally met with, where no symptoms, referable to disease of the stomach, or spasmodic affection of the osophagus or pharynx, were present.

* Gilman's Dissertation on the Bile of a Rabid Animal, sect. I. \&c. \&c. 
The appearances mentioned in some of the dissections given of dogs, deviate more from the character of simple turgescence, than most of those stated to have been observed in the human subject; inasmuch as there was frequently effusion of blood seen between the villous and muscular coat of the stomach, or in the substance of the former. The mere action of vomiting will, however, as I have in one case particularly observed, materially increase the redness to be seen, after death, in the stomach of a healthy dog. In attempting, therefore, to establish the pathology of this disease, it is important to discriminate between the effects of inflammation, and the influence which the violent spasmodic affection of the cesophagus and pharynx will have, not only upon the mucous membrane covering those parts, but upon the villous coat of the stomach itself, by being propagated downwards within the cardiac orifice. For it is very probable, that violent spasmodic action of muscles, may produce a well marked influence on a superincumbent mucous coat, particularly when such coat is extremely lax and vascular, as is that of the stomach.

With regard to the employment of blood-letting in hydrophobia, I would observe, that if its utility were even confirmed by the most irrefragable evidence, it would not. be conclusive as to the inflammatory nature of this disease. The effects of this remedy are not to be limited to the mere re- 
moval of inflammation, or inflammatory disposition. It is not employed with this view in apoplexy, where it is often of the most decided benefit; and there may be effects produced in the body, particularly on the nervous system, by the copious abstraction of blood, for which the present state of pathological knowledge is not qualified to account. 

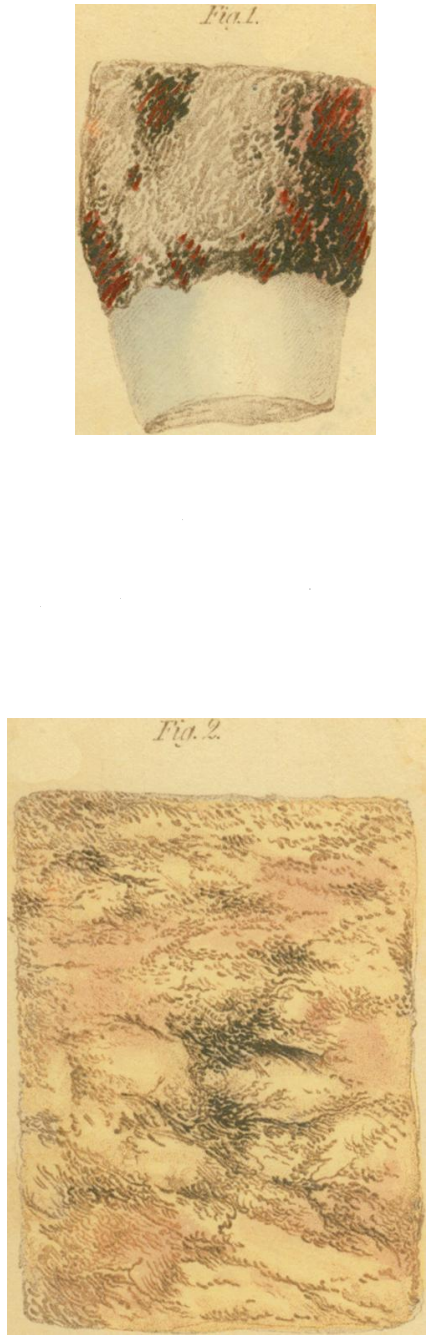
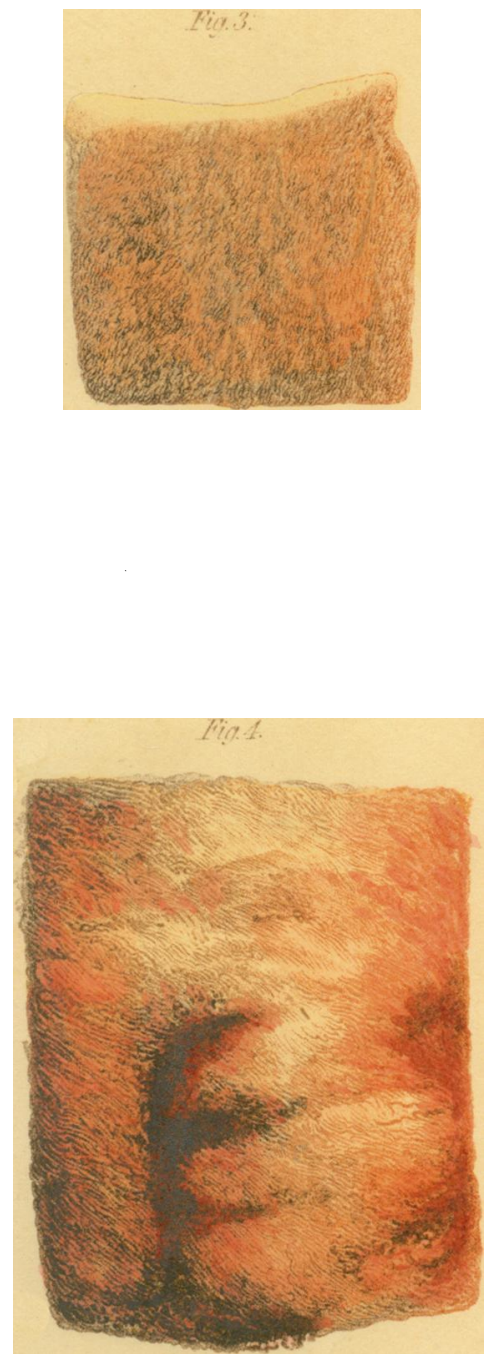

Finomend brizitherent 
$\operatorname{Dol} 4$

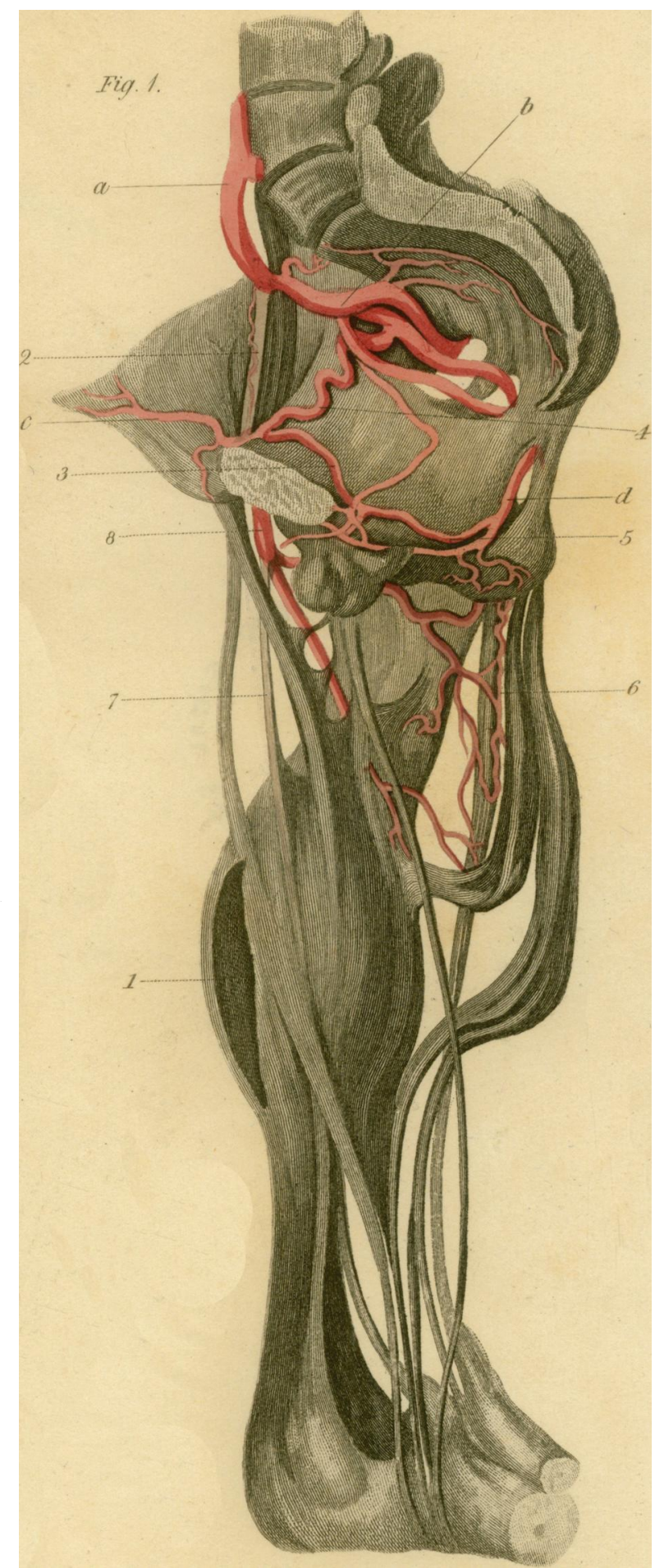



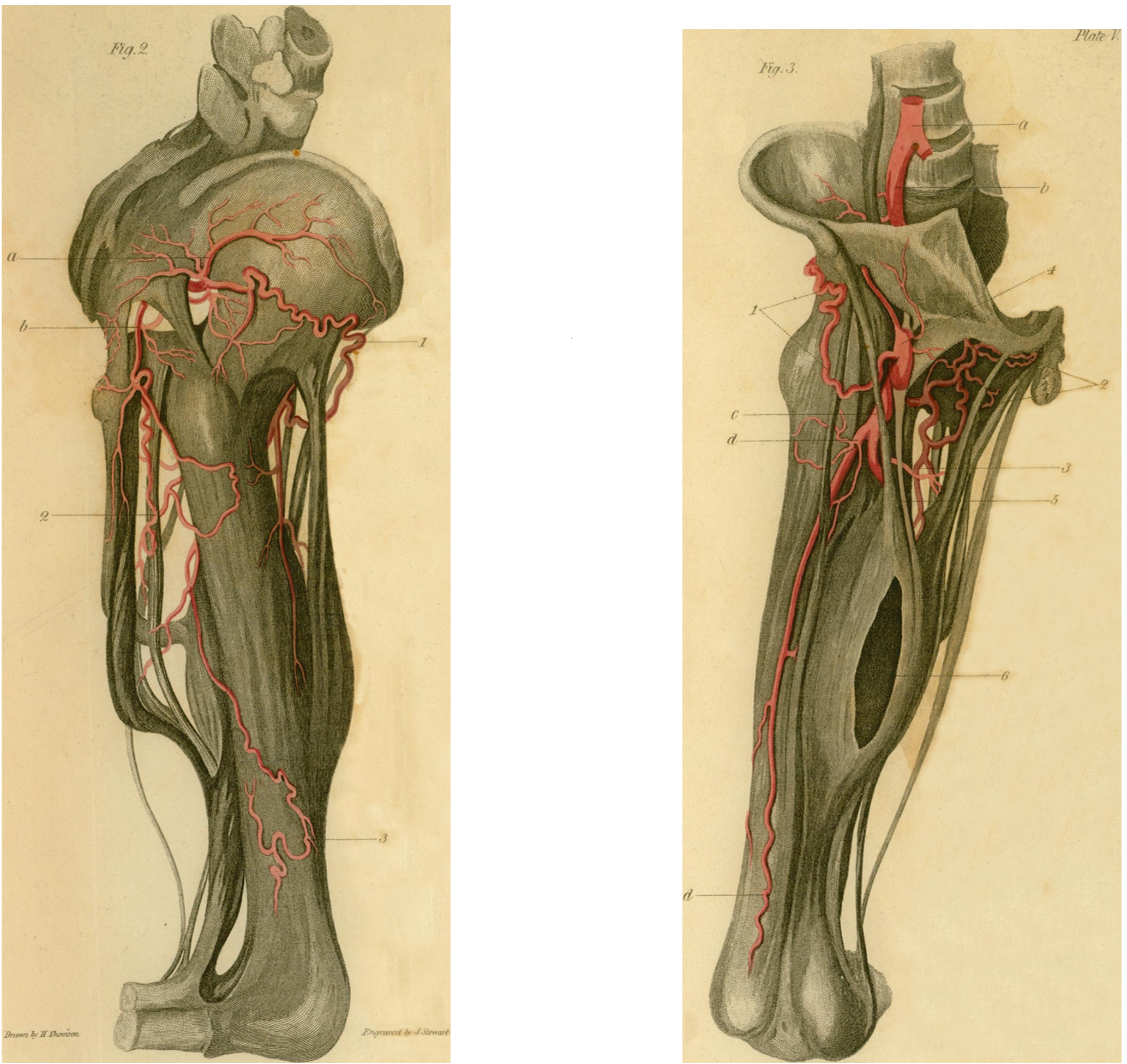